\title{
EXPLORING INDIAN TRADITIONAL MEDICINAL SOURCES AS PROPHYLACTIC STRATEGY AGAINST COVID-19
}

\author{
Jigni Mishra ${ }^{1}$ and Kshipra Misra ${ }^{1 *}$ \\ ${ }^{1}$ Save The Environment, Kolkata, India
}

Received on: 17.06 .2020

Revised on: 28.06 .2020

Accepted on: 30.06 .2020

\begin{abstract}
Coronaviruses have engendered many instances of widespread epidemics across the globe in the past couple of decades. The severity of diseases caused by coronaviruses is complicated manifold due to their characteristic hypermutations which pose the biggest obstacle in delineating any specific vaccine or drug against these viral strains. The world at present is battling the ongoing novel coronavirus disease 2019 (Covid-19), caused by SARS-CoV-2 virus. Covid-19 has claimed about 4, 00, 000 lives as of 15 June 2019 since early reports of the outbreak in December 2019. The unavailability of a particular treatment strategy has resulted in a rising trend of active Covid-19 cases and casualties. Such a scenario has motivated the healthcare professionals and general public to adopt a preemptive approach by accentuating overall immunity as well as maintaining personal hygiene and social distancing. The past few months have witnessed increased awareness and acceptance of the age old convention of Ayurveda and traditional medicines for augmentation of immunity and/or subsiding the symptoms against SARS-CoV-2 infection. In line of this, the present review focuses on the importance of various traditional medicinal sources as preventive leads against the pandemic. The sources discussed here include plants namely, Curcuma longa and Hippophae rhamnoides, and medicinal mushrooms i.e., Cordyceps sinensis and Ganoderma lucidum. Evidence- based antiviral properties of extracts and fractions prepared from these traditional medicines, along with their prospective use for immunity enhancement and supportive healthcare in novel coronavirus disease have also been elucidated. Also, the interplay between Covid-19 and hypoxia-induced ailments of lungs have been elaborated for exploring the usage of aforesaid traditional medicinal sources, as prophylactics against the currentpandemic.
\end{abstract}

\section{Keywords}

Covid-19; preventive medicine; prophylactic; SARS-CoV-2; traditional medicinal system.

\section{Introduction}

The ongoing 'Covid-19' pandemic also known as 'novel coronavirus disease 2019' is a form of respiratory ailment, accompanied by symptoms typical to flu, for instance cough, fever, shortness of breath, and as recently added, a loss in perception of smell and taste [1]. In extreme severities, acute respiratory stress syndrome, associated multiple organ failure and blood coagulation are also observed [2]. Covid-19 spreads chiefly by respiratory droplets released by diseaseridden individuals while coughing and sneezing. The pandemic has already claimed 4, 40, 000 lives across the world, with 8 million active cases as of 15 June, 2020 [3].Similar to all the main epidemic and pandemic outbreaks recorded so far in history, namely, West Nile fever, severe acute respiratory syndrome (SARS), avian influenza/bird flu,
Middle East respiratory syndrome (MERS), Ebola hemorrhagic fever and Zika fever, the Covid-19 disease is also caused by a virus, i.e., severe acute respiratory syndrome coronavirus 2 (SARS-CoV-2). The simple structure of viruses comprising a protein coat and genetic material (DNA or RNA), permits easy assembly and rapid multiplication of viruses in the host cells, thus accounting for their high contagion rates. Inside the host cells, virions cause several cytopathological effects like cell lysis, apoptosis and instigate host cell machinery to produce multiple copies of virus particles [4].

The viruses having RNA as genetic material are usually much more virulent than their DNA equivalents, due to absence of proofreading function in viral RNA polymerases. An 
example of viral family with RNA genome is 'coronaviruses' which cause infectious diseases like common cold, hepatitis A, hepatitis C, measles, polio and the current Covid-19 pandemic. RNA viruses demonstrate unrelenting hyper mutations and reassortment, hence, the task of devising vaccines or any antiviral drug becomes a grim imposition. This necessitates the role of preventive strategies like the use of traditional medicinal sources, as deliberated in the upcoming paragraphs. In this perspective, the presentreview illustrates the pathophysiology of ailments inflicted by coronaviruses, and the importance of traditional medicinal sources in treatment or prevention of Covid-19, with special focus on Indian turmeric, sea buckthorn, keera jhari and reishi as putative natural alternatives against viral incidences.

\section{Coronaviruses}

Coronaviruses are categorized under RNA viruses having a lipid bilayer to which the envelope (E), spike (S) and membrane (M) proteins are attached (Figure 1). Entry into host cells is by attachment via spike protein. Once the virus has gained entry into target host cytoplasm, its positive-sense single-stranded RNA genome replicates arbitrated by RNA dependent RNA polymerase [5]. Coronaviruses trigger respiratory tract infections in human beings, ranging from common cold to serious illnesses such as SARS, MERS and Covid-19. The causal strain of Covid-19 -'SARS-CoV-2' is the seventh known coronavirus to wreak havoc in human population, the earlier ones being 229E, NL63, OC43, HKU1, SARS-CoV and MERS-CoV [6]. Particularly, SARS$\mathrm{CoV}-2$ is a beta coronavirus categorized under 'coronaviridae 'family. Its structure is depicted in Figure 1 [7].

\section{Pathophysiology of novel coronavirus disease}

SARS-CoV-2 virus primarily infects the respiratory tract in human host. Its spike protein renders accessibility to the epithelial cells in lung alveoli. The virus gets attached with the angiotensin-converting enzyme 2 (ACE2). ACE2 is plentifully present in alveolar cells, hence lungs become the predominant target in SARS-CoV-2 infection. Other organs where ACE2 is expressed are gut, heart, kidney and brain thus, Covid-19 leads to severe gastric, duodenal and rectal

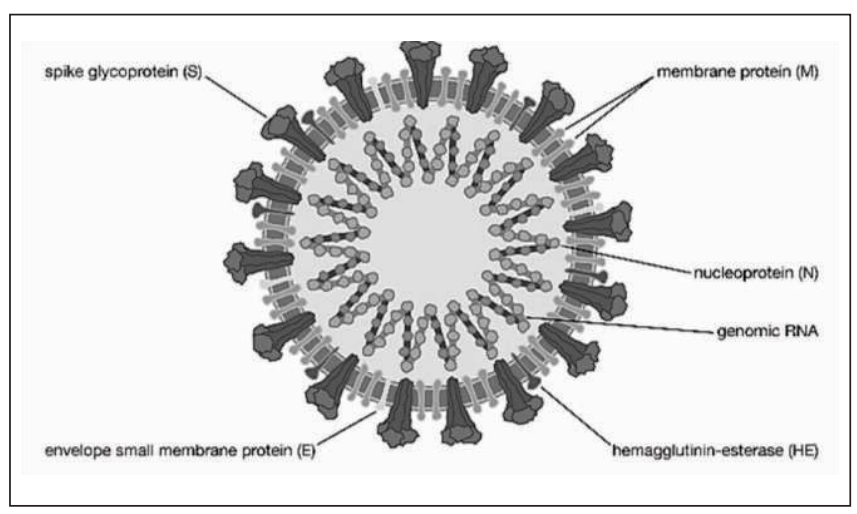

Figure 1: Structure of SARS-CoV-2 infections, acute myocardial risks, kidney injuries and also, complications in central nervous system [8-10]. Etiology of Covid-19 proves that all the vital organs, in more or less severities depending on the patient' s immunity, are affected. Hence, individuals with already prevailing comorbidities like diabetes, hypertension, heart diseases, kidney diseases are more susceptible to Covid-19.

\section{Ongoing medical approaches for management of Covid-19}

The high contagion rate and rapid mutation tendency of SARS-CoV-2are the main roadblocks in developing a substantial vaccine or drug against the novel coronavirus disease. These factors have steered the status of Covid-19 from epidemic in December 2019 to pandemic in March, 2020.Several research groups the world over are persistently striving to delineate an anti-SARS CoV-2 vaccine; however, it is a long way before the final phase trials are completed [11]. The Union Health Ministry of the Government of India has stated that, as of May 25, 2020, four prospective vaccine candidates are being considered for clinical trial phases.

In the unavailability of a steadfast vaccine candidate, certain antiviral drugs are being administered to Covid-19 patients, to restrict the viral flare. The drugs currently in the task arelopinavir, chloroquine phosphate, arbidol, ribavirin, favipiravir, etc. The named antiviral medications follow varied mechanisms of action, for example, acting as structural analogues, reducing replication rate, deterring RNA-dependent RNA polymerase activity, etc. However, all these drugs exhibit many side effects like nausea, diarrhea, and complications in patients with already existent chronic illnesses. So far, hydroxychloroquine in conjunction with azithromycin has been conceded as the best medication combination against the SARS-CoV-2 infection $[12,13]$. Although hydroxychloroquine decreases IL-6 production implicated in cytokine storm in Covid-19 patients, however, this this drug is effective only during the early stages of viral entry and replication and not in the advanced stages of the disease.[14].

Amidst this, the World Health Organization (WHO) and the Indian Council for Medical Research (ICMR), since the beginning of the pandemic phase, have recommended to count on 'traditional' or 'complementary' medicinal systems and preventive approaches against contracting Covid-19 or alleviating the symptoms [15]. In this regard, the present review intends to discuss the efficacy of some traditional medicinal sources already recognized in literature as antiviral therapeutics and suggest their prospective prophylactic abilities against Covid-19. Traditional medicines have been amply proven to be resourceful preventive and alternative modes of healthcare. Therefore, this article highlights the role of some natural herbs e.g.: Indian turmeric and sea buckthorn, and medicinal mushroomsi.e., keerajhari and reishi against Covid-19 disease and its associated symptoms. 


\subsection{Traditional medicinal system}

Traditional medicinal system is a popular strategy of alternative healthcare that has been well represented in traditional Chinese medicine (TCM), traditional Tibetan medicine and Indian systems of Ayurveda, Siddha and Unani since past many centuries. Descriptive literature is plentifully available about the use of therapeutic principles sourced from plant, animal and mineral sources in curing several illnesses or maintaining wellbeing. The traditional medicinal system of India is home to diverse medicinal plants and mushrooms that possess many pharmacological properties $[16,17]$. The Indian traditional system of healthcare, i.e., Ayurveda ('ayus' meaning 'life' + 'veda' meaning 'knowledge') is adopted as primary healthcare by more than half of the country's population, owing to its ease of accessibility, affordability and holistic purposes. Ayurvedic or naturopathic restorative formulations provide significant respite from numerous illnesses or diseased conditions. The pharmacological effects of these traditional preparations are at par with modern allopathic drugs. In Ayurved literature, Maharishi herbal mixtures have been mentioned to be stronger antioxidants than ascorbic acid and a-tocopherol [18]. The rising popularity of traditional medicine has motivated the establishment of The Ministry of Ayurveda, Yoga \& Naturopathy, Unani, Siddha and Homoeopathy (AYUSH) by Government of India where AYUSH is dedicatedly working on research and dissemination of indigenous traditional medicines.

Not only in India, but also in other countries, traditional medicinal system is an established approach for wellness management and improvement of human health. In China, $40 \%$ of primary health care consists of traditional medicines where natural sources are a central component of remedial measures. Similar trends in Asian and South American countries have also been cited [19]. Traditional medicine has gathered impetus in developed countries like Australia, Belgium, Canada, France and the United States of America [20]. The benefit of not having any side effects is the major contributing factor to the popularity of traditional medicines worldwide.

\subsection{Traditional medicines as a workforce to augment immunity and restrict viral flare}

Both TCM and Ayurveda describe the use of several herbs and other natural sources for enhancing individual immunity. E.g.: Panax ginseng (ginseng) herb has recuperative potential in immune-compromised cancer patients [21]. Ginseng fractions also aid in helper $\mathrm{T}$ cellmediated immune response against viral infections caused by parvoviruses, rhino viruses, influenza viruses, HIV, etc. [22]. In addition to above, other herbal preparations from Radix spp., Fructus forsythiae (Lanhua), Andrographis paniculata (chirayata), etc. are known to exert inhibitory effects on influenza and hepatitis viruses [23]. Traditional drugs have also displayed efficacy against specific coronavirus strains as explained below.
4.2.1. Traditional medicines: targeting antiviral action against coronaviruses

Traditional medicines are known to be appreciable preventive agents against infections caused by coronaviruses. In the 2002-2004 SARS epidemic in China, general public was suggested to intake traditional medicines as a prophylactic. Here, 'glycyrrhizin' collected from liquorice root curbed the replication of SARS viruses [24]. Chinese herbs in adjunction with modern medication helped in recovery of SARS patients by bringing about antipyretic action, clearance of fluid accumulation in lungs and reduced dependency on steroids. Even for the ongoing Covid-19, TCM herbal remedies have been endorsed by Chinese healthcare experts to contain and eradicate theSARS-CoV-2 infliction. A TCM formulation named 'qingfeipaidu decoction (QPD)' made up of 21 herbs has been reported to be seemingly efficient in treating Covid-19 by repressing viral replication and improving overall immune response. The recipe of QPD includes medicinal herbs such as Bupleuri radix, Cinnamomiramulus, Ephedraeherb, Glycyrrhizae radix, Scutellariae radix and Zingiber spp. [25].

In a manner similar to TCM, traditional Indian medicines have been increasingly reported to be highly reliable in enhancing individual immunity and downgrading pathogenesis of SARS- CoV-2 in Covid-19 patients. An Ayurvedic formulation comprising Elettaria cardamomum (cardamom), Piper nigrum (black pepper), Syzygium aromaticum (clove), With a $n$ i a s o m n if e r a ( a s h w a g a $\mathrm{n} \mathrm{d} \mathrm{h} \mathrm{a} \mathrm{)} \mathrm{a} \mathrm{nd}$ Zingiber officinale (ginger) has been seen to impart immune- stimulant action in HIV positive patients by elevating levels of IFN- $\gamma$, interleukin-2 (IL-2) and tumor necrosis factor-alpha (TNF- $\alpha$ ) [26]. Polyphenols and tannins present in Triphala, containing equal proportions of Emblica officinalis (amla), Terminalia belerica (baheda) and Terminalia chebula (haritaki) are known to have antiviral properties and increase immunity by augmenting neutrophils action [27]. Previously, virucidal effects of Eugenia jambolana (jamun) extracts were observed on H5N1 avian influenza viral strain [28].

\subsubsection{Traditional medicines as therapeutic strategy against Covid-19}

Several research groups in India have insisted upon increasing an individual's overall immunity as a beneficial preventive approach against contracting Covid-19. For this, numerous traditional medicinal herbs with well-established recuperative uses have been proposed. One among them is W. somnifera commonly known as 'ashwagandha' has been elucidated as a remedial means against COVID-19. The underlying action is said to be via 'withanones' which influence helper T cells (Th-1/Th-2) immunity [29]. Keeping in consonance with reported medical uses of ashwangandha, generation of immunity against viral by IFN- $\gamma$ responses and repression of immune inflammatory parameters such as IL-1, IL-6 and TNF- $a$ have been suggested. Yet other Ayurveda 
concoctionswith ingredients like Asparagus racemosus (shatavari), Phylanthus emblica (amalaki) and Tinospora cordifolia (guduchi) have also been shown to improve immunity in individuals infected with SARS-CoV-2 [30].

The Ministry of AYUSH has advocated consumption of Chyavanprash in order to strengthen immunity. Warm decoctions ('kaadha') containing Ocimum sanctum (tulsi), Cinnamomum verum (cinnamon), black pepper and dried $\mathrm{Z}$. officinale (sounth) have also been advised. Golden milk, simply milk with an added portion of Curcuma longa (Indian turmeric/haldi) powder is being administered to Covid-19 patients as a means to ensure faster recovery[31].

Patanjali foundation's SwasariRas, a methodical preparation of Glycyrrhiza glabra (liquorice/mulethi), S. aromaticum (clove), cinnamon, Pistacia chinensis (kakdasingi), sunthi, Piper longum (pepper), mica ash/abhrakbhasma and kapardak bhasma plus extracts of ashwagandha, guduchi, tulsi, already recognized remedial actions against phlegm and cough, has been advised for preventive action against Covid19. Consumption of all these compounds have been advised in addition to ICMR-prescribed allopathic treatments.

It may be especially noted that all the aforementioned traditional medicinal preparations are extremely rich in secondary metabolite content like alkaloids, flavonoids, glycosides, phenolic, proteins, sterols, sugar alcohols, etc. that in turn fortifies their concept of being utilized as alternative medicines against viral outbreaks [29].

\subsection{Application of traditional medicinal sources as prophylactic against Covid-19}

Current research outcomes mention that SARS-CoV-2 is responsible for mucus build up in lungs that further aggravates to pulmonary edema [32]. Severe hypoxemia followed by loss of perfusion regulation and hypoxic vasoconstriction in affected lungs has been reported [33]. With disease progression, elevation in host inflammatory reaction causes onset of hypoxia that worsens one's pulmonary abilities [34]. In a breakthrough study, substantial similarities in pathophysiology of Covid-19 and high altitude pulmonary edema have been derived. These similarities embody lowered partial pressure of oxygen in tissues, patchy infiltrates in computerized tomography-based imaging of lungs and bilateral diffuse alveolar damage. An increased lung capacity and higher systemic immunity is being sounded as a better way to gain faster recovery from the pandemic [35].

Keeping in accordance with the observations in preceding paragraph, this review article discusses the efficacy of four Indian traditional medicinal sources, widely recognized in traditional medicinal scriptures and contemporary research alike, for their efficacy against high altitude induced hypoxia and other respiratory ailments, as promising preventive agents against Covid-19. These sources include medicinal plants namely, Curcuma longa (Indian turmeric) and Hippophae rhamnoides (sea buckthorn), and medicinal mushrooms i.e., Cordyceps sinensis (keera jhari) and Ganoderma lucidum (reishi). Their highly efficient hypoxia protective action in addition to antiviral and immuneenhancing effects have been iterated below, thus, strengthening their prospects as putative therapeutics against the ongoing pandemic.

\subsubsection{Curcuma longa}

C. longa or Indian turmeric is pharmacologically the most important species in Curcuma genus. Literature cites that thirteen curcuminoids isolated from $C$. longa have exhibited effective inhibition of H1N1 swine flu virus by disrupting neuraminidase activity [36]. Similarly, aqueous and ethanol extracts of $C$. longa have been reported to inhibit the replication of avian influenza virus $\mathrm{H} 5 \mathrm{~N} 1$ by augmenting levels of TNF- $\alpha$ and IFN- $\beta$ mRNA [37]. It has also been illustrated that curcumin supplementation normalizes the quantities of hypoxia inducible factor-1a (HIF-1a) - an established biochemical marker of hypoxia conditions in tissues along with upregulating hemeoxygenase-1 (HO-1) and nuclear factor (erythroid-derived 2)-like 2 factor ( $\mathrm{Nrf2}$ ), thus, bringing about pulmonary surfactant homeostasis under hypoxic [38]. Even for the novel coronavirus disease, the immune - enhancing and defensive action of $C$. longa has clearly been projected. [39].

\subsubsection{Hippophae rhamnoides}

H. rhamnoides, commonly referred to as 'sea buckthorn', is known to display significant antiviral properties against specific viral strains. For example, sea buckthorn water extracts inhibit viral neuraminidase of the influenza virus; obstructs the replication of herpes virus and also appreciably controls the rapid replication of HIV [40-41]. $H$. rhamnoides bud dry extract was found to reduce replication of the influenza-A and H1N1 virus in vitro [42]. In yet another study, sea buckthorn leaf extract demonstrated significant anti-dengue activity [43]. The importance of sea buckthorn in averting hypoxia effects are well represented [44]. $H$. rhamnoides leaf extract significantly reduces hypoxia- induced transvascular permeability in lungs. This leaf extract imparted significant protection against hypoxia-induced transvascular permeability by stabilizing the levels of reduced glutathione and antioxidant enzymes [45]. In CHR multiple stress setting, aqueous extract of $H$. rhamnoides efficiently decremented malondialdehyde, normalized catalase and restored the amounts of reduced glutathione and superoxide dismutase [46]. Furthermore, H. rhamnoides is considered to be a considerable repository of vitamin $\mathrm{C}$. It has been recently verified that vitamin $\mathrm{C}$ encourages immunity enhancement by augmenting differentiation and proliferation 
of B and T lymphocytes cells, and is specifically beneficial in preventing and treating respiratory and vascular infections. The role of vitamin $\mathrm{C}$ in providing resistance against SARSCoV-2 infection has been established by now. Hence, $H$. rhamnoides can certainly be regarded as a promising potent preventive herb against the coronavirus infection [47].

\subsubsection{Cordyceps sinensis}

'Cordycepin', the major marker compound of $\mathrm{C}$. sinensis/keera jhari has antiviral action against Epstein-Barr virus (EBV), HIV and influenza virus [48]. It also quells the characteristic morphological changes occurring in human lymphocytes after infection with EBV [49-50]. Infection with hepatitis $\mathrm{B}$ virus (HBV) is contained by $\mathrm{C}$. sinensis extracts by bringing about an increase in humoral and cellular immunity in murine models [51]. Also, C. sinensis aqueous extracts have shown immunomodulatory action in mice with lymphoma by improving phagocytic activity of peritoneal macrophages [52]. In the present context of Covid-19, the use of C. sinensis as an immunomodulatory agent against the2001 SARS outbreak is worth mentioning. Reports accrediting C. sinensis for its antiviral as well as bronchioalveolar muscle relaxing effects, thus, aiding in lung decongestion are available. The effect of C. sinensis in regulating $\mathrm{T}$-cell, natural killer (NK) cell and macrophagesfunction as antiviral defense in SARS patients paves its way as an anti-Covid-19 therapeutic as well [53]. Aqueous and alcoholic extracts of C. sinensisare known to mollify hypoxia induced stress in human lung epithelial cell lines (A549) via Nrf2 activation and in murine neuronal hippocampal cell lines (HT22) by reducing inflammatory cytokines [54-55]. Also, in a recent study conducted on murine model, phenolic fractions of Indian variety of $\mathrm{C}$. sinensis have been observed to impart protective action against CHR stress, by moderating dysregulated levels of malondialdehyde, superoxide dismutase and glutathione in lungs, heart and muscle tissues [56]. Combined, the observations described herestrongly put forth the salubrious role of keerajhari in prophylaxis of Covid-19.

\subsubsection{Ganoderma lucidum}

G. lucidum, or popularly called 'reishi' mushroom, is widely recognized both in traditional medicine and modern research for its numerous pharmacological properties. Its rich content of alkaloids, flavonoids, phenolics and triterpenes elicit antiviral effects against different viruses. As instance, ganoderic acids obtained from G. lucidum fruiting bodies display antiviral activity against HIV and EpsteinBarr virus [57]. Ganodermadiol exhibits inhibitory effect in herpes simplex virus type [58]. Aqueous extracts and methanolic fractions of reishi mushroom have proven virucidal action against human papilloma virus and influenza A virus, respectively [59]. Besides, there are ample scientific reports vouching for the immune enhancing role of $G$. lucidum. Polysaccharides and glycoproteins present in $G$. lucidum upregulate the major histocompatibility complex (MHC) expression in melanoma cell lines; treatment with G. lucidum fractions lead to elevated cytokine secretion from immune cells, thus, boosting innate and adaptive immunity [61-62]. G. lucidum as a protective agent against hypobaric hypoxia has been authenticated in recent scientific literature. Aqueous and ethanolic extracts from reishi mushroom have been emulated to be cardioprotectant in murine cardiomyoblasts, $\mathrm{H} 9 \mathrm{c} 2$ under simulated hypoxic environment. Here, addition of G. lucidum extracts have been shown to stabilize HIF-1a, caspase-3 and caspase-7 [63]. In a cold, hypoxia, restraint (CHR) multiple stress set up, water extract of G. lucidum mycelium has been demonstrated as an adaptogen by regulating oxidative biomarkers like malondialdehyde, reduced glutathione and superoxide dismutase [64]. The promising action of G. lucidum as an antiviral, immune enhancing and anti-hypoxia therapeutic bolster its applicability in supportive care of Covid-19.

An overall interplay in the levels of various oxidative stress biomarkers that are modulated after supplementation with different traditional medicinal plants or mushrooms, whilst protecting against hypoxia stress is depicted in Figure 2 [65].

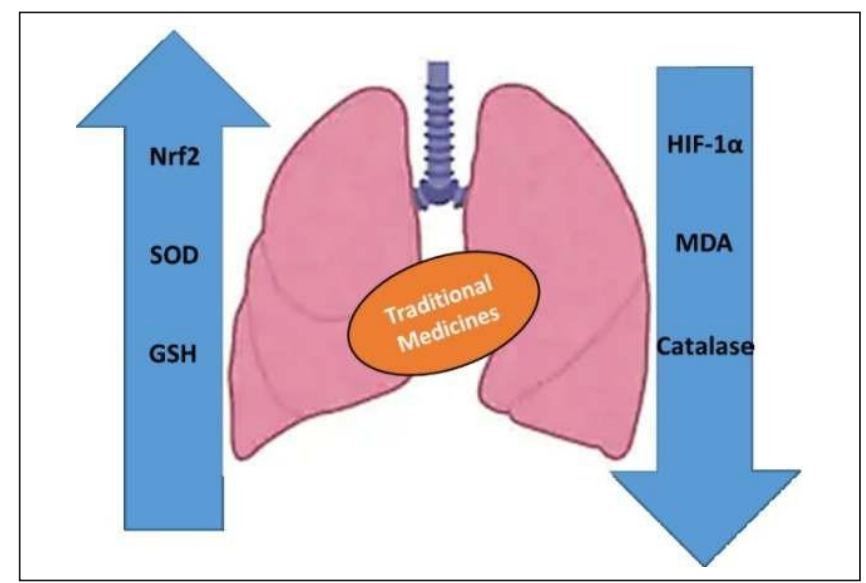

Figure 2: Modulation of oxidative stress markers by traditional plants/ mushrooms under hypoxia, indicative of their prophylactic activity against Covid-19

\section{Conclusion}

In the ongoing pandemic situation, WHO and ICMR have asserted the importance of improving immunity and use of sanitation measures to prevent contracting Covid-19. It is the need of the hour to explore our country's vast reserve of traditional medicines to bolster immunity. Research conducted by AYUSH, Patanjali foundation and many other scientific groups has to be coordinated with ICMR guidelines. Also, validated interdisciplinary approaches could be undertaken to translate the aforementioned traditional herbal immunity-boosters and immuno- 
modulators into 'herbal adjuvants' or 'prophylactic products'. The absence of a guaranteed anti-Covid-19 vaccine/drug candidate, has made it even more essential to recommend the use of traditional medicines as preventive and alternative remedies, along with personal hygiene measures, to emerge victorious amidst these pandemic times.

\section{Conflict of interest}

The authors have no conflict of interest to declare.

\section{Acknowledgements}

The authors would like to heartily thank all the front line warriors who are persistently striving to help us win the battle against Covid-19.

\section{References}

1. Moein ST, Hashemian, SM, Mansourafshar B, Khorram-Tousi A, Tabarsi P, Doty RL. Smell dysfunction: a biomarker for COVID-19. International Forum of Allergy \& Rhinology. 2020.

2 Mehta P, McAuley DF, Brown M, Sanchez E, Tattersall RS, Manson JJ. COVID-19: consider cytokine storm syndromes and immunosuppression. The Lancet. 2020;395:1033-1034.

3 COVID-19 Dashboard by the Center for Systems Science and Engineering (CSSE) at Johns Hopkins University (JHU)". ArcGIS. Johns Hopkins University. Retrieved 15 June 2020.

4 Collier $\mathbf{J}$, Heathcote $\mathbf{J}$. Hepatitis $\mathrm{C}$ viral infection in the immunosuppressed patient. Hepatology. 1998; 27:2-6.

5 Simmons G, Zmora P, Gierer S, Heurich A, Pöhlmann S. Proteolytic activation of the SARS-coronavirus spike protein: cutting enzymes at the cutting edge of antivir al research. Antiviral Research. 2013;100: 605- 614.

6 Zhu N, Zhang D, Wang W, Li X, Yang B, Song J, Zhao X, Huang B, Shi W, Lu R, Niu P. A novel coronavirus from patients with pneumonia in China. New England Journal of Medicine. 2020;382: 727-733.

7. https://www.britannica.com/science/coronavirus-virusgroup

8 Verdecchia P, Cavallini C, Spanevello A, Angeli F. The pivotal link between ACE2 deficiency and SARS-CoV-2 infection. European Journal of Internal Medicine, 2020; https://doi.org/10.1016/j.ejim.2020.04.037.

9. Zheng YY, Ma YT, Zhang JY, Xie X. COVID-19 and the cardiovascular system. Nature Reviews Cardiology. 2020; v. 17, p. 259-260.

10. Hamming I, Timens W, Bulthuis ML, Lely AT, Navis G, van GoorH. Tissue distribution of ACE2 protein, the functional receptor for SARS coronavirus: A first step in understanding SARS pathogenesis. The Journal of Pathology. 2004; 203: 631-637.
11. Callaway E. Coronavirus vaccine trials have delivered their first results - but their promise is still unclear. Nature News. 2020; https://www.nature.com/ articles/d41586-020-01092-3 (29 May, 2020).

12 Singh AK, Singh A, Shaikh A, Singh R, Misra A. Chloroquine and hydroxychloroquine in the treatment of COVID-19 with or without diabetes: A systematic search and a narrative review with a special reference to India and other developing countries. Diabetes \& Metabolic Syndrome: Clinical Research \& Reviews. 2020; 14: 241246.

13 Gautret P, Lagier JC, ParolaP, Meddeb L, Mailhe M, Doudier B, Courjon J, Giordanengo V, Vieira VE, Dupont HT, Honoré S. Hydroxychloroquine and azithromycin as a treatment of COVID-19: results of an open-label non-randomized clinical trial. International Journal of Antimicrobial Agents. 2020;105949.

14 Zhou F, Yu T, Du R, Fan G, Liu Y, Liu Z, Xiang J, Wang Y, Song B, Gu X, Guan L. Clinical course and risk factors for mortality of adult inpatients with COVID-19 in Wuhan, China: a retrospective cohort study. The Lancet. 2020;395: 1054-1062.

15. Lu Q, Shi Y. Coronavirus disease (COVID-19) and neonate: What neonatologist need to know. Journal of Medical Virology. 2020; 92: 564-567.

16. Bhat GP, Surolia N. In vitro antimalarial activity of extracts of three plants used in the traditional medicine of India. The American Journal of Tropical Medicine and Hygiene. 2001;65:304-308.

17. Ballabh B, Chaurasia OP. Traditional medicinal plants of cold desert Ladakh - used in treatment of cold, cough and fever. Journal of Ethnopharmacology. 2007;112: 341-349.

18 Sharma HM, Hanna AN, Kauffman EM, Newman HA. Inhibition of human low-density lipoprotein oxidation in vitro by Maharishi Ayur-Veda herbal mixtures. Pharmacology Biochemistry and Behavior. 1992;43: 1175-1182.

19. Kayarohanam S, Kavimani S. Current trends of plants having antidiabetic activity: A Review. Journal of Bioanalysis and Biomedicine. 2015;7: 55- 60.

20. Zhang X. Integration of traditional and complementary medicine into national health care systems. Journal of Manipulative \& Physiological Therapeutics. 2000; 23: 139- 140

21. Sun XB, Matsumoto T, Yamada H. Purification of immune complexes clearance enhancing polysaccharide from the leaves of Panax ginseng, and its biological activities. Phytomedicine. 1994; 225-231.

2 Block KI, Mead MN. Immune System Effects of Echinacea, Ginseng, and Astragalus: A Review. Integrative Cancer Therapies. 2003; 2: 247-267. 
2. Li T, Peng T. Traditional Chinese herbal medicine as a source of molecules with antiviral activity. Antiviral Research. 2013;97:1-9.

24 Cinatl J, Morgenstern B, Bauer G, Chandra P, Rabenau H, Doerr HW. Glycyrrhizin, an active component of liquorice roots, and replication of SARSassociated coronavirus. The Lancet. 2003; 361: 20452046.

25. Yang R, Liu H, Bai C, Wang Y, Zhang X, Guo R, Wu S, Wang J, Leung E, Chang H,Li P. Chemical composition and pharmacological mechanism of QingfeiPaidu Decoction and Ma Xing Shi Gan Decoction against Coronavirus Disease 2019 (COVID19): in silico and experimental study. Pharmacological Research. 2020;104820.

26. T h a r a k a n S T, K u t t a n G, K u t t a n R . Immunostimulatory action of AC II-Anayurvedic formulation useful in HIV. Indian Journal of Experimental Biology. 2008; 46: 47- 51.

27. Gowda DV, Muguli G, Rangesh PR, Deshpande RD. Phytochemical and pharmacological actions of Triphala: Ayurvedic formulation- A review. International Journal of Pharmaceutical Sciences Review and Research. 2012; 15: 61- 65.

28 Sood R, Swarup D, Bhatia S, Kulkarni DD, Dey S, Saini M, Dubey SC. Antiviral activity of crude extracts of Eugenia jambolana Lam. against highly pathogenic avian influenza (H5N1) virus. 2012; 50: 179- 186.

29. Varshney A, Balkrishna A, Singh J. Withanone from Withaniasomnifera may inhibit novel coronavirus (COVID-19) entry by disrupting interactions between viral S-protein receptor binding domain and host ACE2 receptor. Res e a r ch Square . 2020 ; d o i : https://dx.doi.org/10.21203/rs.3.rs-17806/v1.

30. Patwardhan B, Chavan-Gautam P, Gautam M, Tillu G, Chopra A, Gairola S, Jadhav S. Ayurveda rasayana in prophylaxis of Covid-19. Current Science. 2020;118: 1158- 1160 .

31. Ayurveda's immunity boosting measures for self-care during COVID 19 crisis. Ministry of AYUSH.2020; https://www.ayush.gov.in/docs/123.pdf (Accessed 1 May, 2020).

32 Hanley B, Lucas SB, Youd E, Swift B, Osborn M. Autopsy in suspected COVID-19 cases. Journal of Clinical Pathology. 2020;73: 239-242.

3 Gattinoni L, Coppola S, Cressoni M, Busana M, Rossi S, Chiumello D. Covid-19 does not lead to a "typical" acute respiratory distress syndrome. American Journal of Respiratory and Critical Care Medicine. 2020; 201: 1299- 1300.
34 Siddiqi HK, Mehra MR. COVID-19 illness in native and immunosuppressed states: a clinical-therapeutic staging proposal. The Journal of Heart and Lung Transplantation . 2020 ; ht t ps:// dx. doi. org/ 10.1016\%2Fj.healun.2020.03.012.

35. Wang LS, Wang YR, Ye DW, Liu QQ. A review of the 2019 Novel Coronavirus (COVID-19) based on current evidence. International Journal of Antimicrobial Agents. 2020; 105948, https://doi.org/10.1016/ j.ijantimicag.2020.105948.

36 Dao TT, Nguyen PH, Won HK, Kim EH, ParkJ, Won BY, Oh WK. Curcuminoids from Curcuma longa and their inhibitory activities on influenza A neuraminidases. Food Chemistry. 2012;134: 21- 28.

37. Sornpet B, Potha T, Tragoolpua Y, Pringproa K. Antiviral activity of five Asian medicinal pant crude extracts against highly pathogenic $\mathrm{H} 5 \mathrm{~N} 1$ avian influenza virus. Asian Pacific Journal of Tropical Medicine. 2017; 10: 871-876.

38 Mathew T, Sarada SK. Intonation of Nrf2 and Hif1-a pathway by curcumin prophylaxis: A potential strategy to augment survival signaling under hypoxia. Respiratory Physiology and Neurobiology. 2018;258: 12- 24.

39. Verma S. In search of feasible interventions for the prevention and cure of novel Coronavirus disease 2019. OSF Preprints. 2020; https://doi.org/10.31219/ osf.io/q6tsc.

40. Shipulina LD, Tolkachev ON, Krepkova LV, Bortnikova VV, Shkarenkov, AA. Antiviral antimicrobial and toxicological studies on seabuckthorn ( Hippophaerhamnoides). In: Singh, V., ed., Seabuckthorn (Hippophae L.): A Multipurpose Wonder Plant, Daya Publishing House, New Delhi. 2005; 471483.

41. Michel T, Destandau E, Le Floch G, Lucchesi ME, Elfakir C. Antimicrobial, antioxidant, and phytochemical investigations of sea buckthorn (Hippophae" rhamnoides L.) leaf, stem, root and seed. Food Chemistry. 2012; 131: 754-760.

42 Torelli A, Gianchecchi E, Piccirella S, Manenti A, Piccini G, Pastor EL, Canovi B, Montomoli E. Sea buckthorn bud extract displays activity against cellcultured influenza virus. Journal of Preventive Medicine and Hygiene. 2015; 56: E51.

4. Jain K, Suryakumar G, Prasad R, Ganju L, Singh SB. Enhanced hypoxic tolerance by seabuckthorn is due to upregulation of HIF-1a and attenuation of ER stress. Journal of Applied Biomedicine. 2016; 14: 71-83. 
4 Manickam M, Tulsawani R. Survival response of hippocampal neurons under low oxygen conditions induced by Hippophaerhamnoides is associated with JAK/STAT signaling. PloS One. 2014; 9: e87694.

45. Purushothaman J, Suryakumar G, Shukla D, Malhotra AS, Kasiganesan H, Kumar R, Sawhney RC, Chami A. Modulatory effects of sea buckthorn (Hippophaerhamnoides L.) in hypobaric hypoxia induced cerebral vascular injury. Brain Research Bulletin. 2008; 77: 246-252.

46 Sharma P, Suryakumar G, Singh V, Misra K, Singh SB. In vitro antioxidant profiling of seabuckthorn varieties and their adaptogenic response to high altitudeinduced stress. International Journal of Biometeorology. 2015; 59: 1115- 1126.

47. Chen L, Hu C, Hood M, Zhang X, Zhang L, Kan J,Du, J. A Novel Combination of Vitamin C, curcumin and glycyrrhizic acid potentially regulates immune and inflammatory response associated with coronavirus infections: a perspective from system biology analysis. Nutrients. 2020; 12: 1193.

48 Pal M, Misra K. Cordyceps sp.: The Precious Mushroom for High-Altitude Maladies.In:Misra, K., Sharma, P., and Bhardwaj, A., eds., Management of High Altitude Pathophysiology, Academic Press, Cambridge. 2018: 93-114.

4. Doetsch PW, Suhadolnik RJ, Sawada Y, Mosca JD, Flick MB, Reichenbach NL, Dang AQ, Wu JM, Charubala R, Pfleiderer W, Henderson EE. Core (2050) oligoadenylate and the cordycepin analog: inhibitors of Epstein-Barr virus-induced transformation of human lymphocytes in the absence of interferon. Proceedings of the National Academy of Sciences of the United States of America. 1981;78: 6699-6703.

50. Ryu E, Son M, Lee M, Lee K, Cho JY, Cho S, Lee SK, Lee YM, Cho H, Sung GH, Kang H. Cordycepin is a novel chemical suppressor of Epstein-Barr virus replication. Oncoscience, 2014;1: 866- 881.

51. Wang J, Liu R, Liu B, Yang Y, Xie J, Zhu, N. Systems pharmacology-based strategy to screen new adjuvant for hepatitis B vaccine from traditional Chinese medicine Ophiocordyceps sinensis. Scientific Reports. 2017; 7: 44788.

52 Yamaguchi N, Yoshida J, Ren LJ, Chen, H, Miyazawa Y, Fujii, Y, Huang YX, Takamura S. Suzuki S, Koshimura S, Zeng FD. Augmentation of various immune reactivities of tumor-bearing hosts with an extract of Cordyceps sinensis. Biotherapy. 1990; 2: 199205.

53 Yan JK, Wang WQ, Wu JY. Recent advances in Cordyceps sinensis polysaccharides: Mycelial fermentation, isolation, structure, and bioactivities: A review. Journal of Functional Foods. 2014;6: 33-47.

54 Singh M, Tulsawani R, Koganti P, Chauhan A, Manickam M, Misra, K. Cordyceps sinensis increases hypoxia tolerance by inducing heme oxygenase- 1 and metallothionein via Nrf2 activation in human lung epithelial cells. BioMed Research International. 2013; article id569206.

5. Pal M, Bhardwaj A, Manickam M, Tulsawani R, Srivastava M, Sugadev R, Misra K. Protective efficacy of the caterpillar mushroom, Ophiocordyceps sinensis (Ascomycetes), from India in neuronal hippocampal cells against hypoxia. International Journal of Medicinal Mushrooms. 2015;17: 829-840.

56. Rajput R, Sharma P, Mishra J, Bhardwaj A, Sharma RK, Singh K, Bansal A, Misra K. Bioactive Fractions from the Chines e Caterpillar Mushroom, Ophiocordyceps sinensis (Ascomycetes) Elucidate Adaptogenic Role Against Hypoxia Stress. International Journal of Medicinal Mushrooms. 2020; In press.

57. Eo SK, Kim YS, Lee CK, Han SS. Possible mode of antiviral activity of acidic protein bound polysaccharide isolated from Ganoderma lucidum on herpes simplex viruses. Journal of Ethnopharmacology. 2000; 72: 475481 .

58 Bisko NA, Mitropolskaya NY. Some biologically active substances from medicinal mushroom Ganoderma lucidum (W. Curt.: Fr.) P. Karst. (Aphyllophoromycetideae). International Journal of Medicinal Mushrooms. 2003; 5: 301-305.

5\%. Hernandez-Marquez E, Lagunas-Martinez A, Bermudez-Morales VH, Burgete-Garcia AI, LeonRivera I, Montiel-Arcos E, Garcı'a-Villa E, Gariglio P, Madrid-Marina VV, Ondarza-Vidaurreta RN. Inhibitory activity of Lingzhi or Reishi medicinal mushroom, Ganoderma lucidum (higher basidiomycetes) on transformed cells by human papillomavirus. International Journal of Medicinal Mushrooms. 2014; 16: 179-187.

60. Mantovani A, Sica A. Macrophages, innate immunity and cancer: balance, tolerance, and diversity. Current Opinions in Immunology. 2010; 22: 231-237.

61. Sun LX, Lin ZB, Li XJ, Li M, Lu J, Duan XS, Ge ZH, Song YX, Xing EH, Li WD. Promoting effects of Ganoderma lucidum polysaccharides on B16F10 cells to activate lymphocytes. Basic clinical Pharmacology \& Toxicology. 2011; 108: 149-154.

62 Bhardwaj A, Misra K. Ganoderma sp.: The Royal Mushroom for High-Altitude Ailments. In: Misra, K., 
Sharma, P., and Bhardwaj, A., eds., Management of High Altitude Pathophysiology, Academic Press, Cambridge. 2018; 115-152.

6. Kirar V, Nehra S, Mishra, J, Saraswat D, Misra K. Lingzhi or reishi medicinal mushroom, Ganoderma lucidum (Agaricomycetes), as a cardioprotectant in an oxygen-deficient environment. International Journal of Medicinal Mushrooms. 2017; 19: 1009-1021.

64 Bhardwaj A, Sharma P, Mishra J, Misra K. Lingzhi or Reishi Medicinal Mushroom, Ganoderma lucidum
(Agaricomycetes) mycelium aqueous extract modulates high-altitude induced stress. International Journal of Medicinal Mushrooms. 2019; 21: 443-458.

6. Mishra J, Misra K, 2020. Management of Covid-19 pandemic: traditional medicines as a prophylactic strategy against coronaviruses. In: Novel Coronavirus (COVID- 19): Past, Present and Future' (e-book) UCOST, Dehradun (Under review). 